\title{
The effective removal of chloramphenicol by the reduced graphene oxide anchored nZVI/aluminum hybrid under neutral conditions
}

\author{
Yujia Yang ${ }^{1}$, Lejin $\mathrm{Xu}^{2, *}$ \\ 1,2 Department of Nuclear Engineering and Technology, School of Energy and Power Engineering, Huazhong University of Science and \\ Technology, Wuhan 430074, P R China
}

\begin{abstract}
In this study, a reduced graphene oxide anchored nZVI/Al hybrid (rGO@nZVI/Al) was synthesized for effective degradation of chloramphenicol (CAP) at neutral $\mathrm{pH}$ just through the activation of dissolved oxygen (DO). The morphology and physicochemical features of rGO@nZVI/Al were characterized with the field emission scanning electron microscopy combined with energy dispersive spectroscopy (SEM-EDS), Brunauer-Emmet-Teller surface area analysis (BET) and X-ray diffraction (XRD). The CAP removal by $\mathrm{rGO} @ \mathrm{nZVI} / \mathrm{Al}$ was conducted at neutral $\mathrm{pH}$, and the performance of rGO@nZVI/Al for DO activation was also estimated in view of the effect of various systems. The reusability of rGO@nZVI/Al was investigated through the cycle tests and the variation of UV spectrum for further application.
\end{abstract}

\section{Introduction}

Recently, the occurrence of antibiotic contaminants in aquatic environment presents strong correlation to the generation of antibiotic-resistant bacteria and antibiotic resistance genes, which has posed potential threats to the ecosystem and human health. To remediate these polluted aqueous environments, various technologies have been developed to remove antibiotics from water, including adsorption[1], photo-degradation[2], catalytic oxidation[3], biodegradation[4], and microwave radiation[5]. Zero valent iron (ZVI) technology, in particular, nanoscale zero valent iron (nZVI), has attracted widely attention in the field of environmental remediation due to its cost-effective supply, convenient application, high reactivity and environmental benign. nZVI technology based on the degradation and adsorption has been recognized as an economical and environmentally friendly method for the remediation of antibiotic contaminated bodies of water matrices. Unfortunately, nZVI particles tend to agglomerate rapidly and can be oxidized easily, which will cause surface passivation and reduce the activity of nZVI. Moreover, for many organic contaminants degraded by nZVI, the removal efficiency of pollutants is strictly limited by the $\mathrm{pH}$ value and other reaction conditions[6]. Therefore, maintaining the reactivity and expanding the application of nZVI have always been a concern for its utilization in pollutant removal.

Immobilization of nZVI on some kinds of supporting materials, such as graphene and bio-char, is a promising strategy to inhibit the aggregation of nano-particles. In our previous study[7], we prepared a catalyst 3D-
GN@nZVI for effective removal of sulfadiazine by the synergism of oxidation and adsorption without adding any oxidants. However, it is unsatisfying to overcome the limitation of $\mathrm{pH}$, and $\mathrm{pH}$ limitation is the main technical difficulty for most nZVI-modified composites to oxidize organic pollutants. Some researchers reported that bimetallic nZVI hybrids, including $\mathrm{Fe} / \mathrm{Cu}[8]$, $\mathrm{Fe} / \mathrm{Ag}[9]$ and $\mathrm{Fe} / \mathrm{Ni}[10]$, were able to alleviate the $\mathrm{pH}-$ dependent degradation of organics by nZVI-based materials. However, for these samples, adding extra oxidants is necessary for the efficient removal of contaminants, which would increase the cost of water remediation. Therefore, to conquer the $\mathrm{pH}$ limitation and to achieve a favorable performance of oxygen activation, it is the key to construct an efficient nZVI-based catalyst, which could impede the iron surface passivation and promote the electron delivery during the reaction.

In the present work, a reduced graphene oxide anchored nZVI/Al hybrid ( $\mathrm{rGO} @ \mathrm{nZVI} / \mathrm{Al})$ was synthesized for effective chloramphenicol (CAP) degradation from water under neutral $\mathrm{pH}$ values in the absence of any extra oxidants. The prepared rGO@nZVI/Al was characterized with the field emission scanning electron microscopy combined with energy dispersive spectroscopy (SEM-EDS), Brunauer-EmmetTeller surface area analysis (BET) and X-ray diffraction (XRD) to investigate its morphology and chemical properties. The experiments for CAP removal were conducted under the DO and Ar conditions without adjusting the $\mathrm{pH}$ value $(\mathrm{pH}=7.5)$, respectively. In addition, compared with some other samples, the performance of DO activation by rGO@nZVI/Al was estimated via the CAP degradation in the presence and

* Corresponding author: xulejin@hust.edu.cn 
absence of $\mathrm{H}_{2} \mathrm{O}_{2}$. The reutilization of $\mathrm{rGO} @ \mathrm{nZVI} / \mathrm{Al}$ was also investigated by the recycling tests combined with the ultraviolet spectra analysis.

\section{Experimental section}

\subsection{Chemicals and agents}

All chemicals used for the study were of analytical reagent grade, including ferrous sulfate heptahydrate $\left(\mathrm{FeSO}_{4} \cdot 7 \mathrm{H}_{2} \mathrm{O}\right)$, aluminum sulfate octadectadate $\left(\mathrm{Al}_{2}\left(\mathrm{SO}_{4}\right)_{3} \cdot 18 \mathrm{H}_{2} \mathrm{O}\right)$ and potassium borohydride $\left(\mathrm{KBH}_{4}\right)$, which were purchased from Sinopharm Chemical Reagent Co., Ltd. The Graphite oxide powder was obtained from Nanjing XFNANO Materials Tech. Co., Ltd. Chloramphenicol $\left(\mathrm{C}_{11} \mathrm{H}_{12} \mathrm{Cl}_{2} \mathrm{~N}_{2} \mathrm{O}_{5} ; 99 \%\right)$ was supplied by the Aladdin Industrial Corporation (Shanghai, China).

\subsection{Preparation and characterization of samples}

The rGO@nZVI/Al was prepared via a simple selfassembly process of liquid-phase reduction mentioned in our previous study[7], and the atomic ratio of $\mathrm{Fe} / \mathrm{Al}$ loading on the rGO matrix was kept at 8:1. Besides, rGO@nZVI and rGO@Al were also prepared in the similar way for comparison.

The morphology of the prepared nanocomposites was observed by S4800 field emission scanning electron microscopy coupled with energy dispersive spectroscopy with the accelerating voltage of $5-15 \mathrm{kV}$; A TriStar II 3flex BET (Brunauer-Emmet-Teller) surface area analyzer was used for the measurement of surface area and pores size by $\mathrm{N}_{2}$-adsorption-desorpotion method. The crystalline patterns were characterized on an XTRA $\mathrm{X}$-ray diffractometer (Switzerland) and $\mathrm{Cu} \mathrm{K} \alpha$ radiation $(\lambda=1.5418 \AA)$ with a scan rate of $4^{\circ} \mathrm{s}^{-1}$. Magnetic measurements were carried out using a vibrating sample magnetometer (VSM Lakeshore7404).

\subsection{Batch experiments and sample analysis}

The degradation of CAP by rGO@nZVI/Al was investigated by using the conventional bottle-point method, and the tests were performed in the $20 \mathrm{~mL}$ serum bottles containing $10 \mathrm{~mL}$ of $20 \mathrm{mg} / \mathrm{L} \mathrm{CAP}$ solution and $0.5 \mathrm{~g} / \mathrm{L}$ sample.

Concentrations of chloramphenicol in solution were determined using a high-performance liquid chromatography (HPLC, Waters 1525, USA) equipped with a C18 reversed-phase column $(5 \mu \mathrm{m}, 4.6 \times 150 \mathrm{~mm})$ and a diode array detector. The mobile phase was methyl alcohol and water $(70: 30, \mathrm{v} / \mathrm{v})$ with a flow rate of 1.0 $\mathrm{mL} / \mathrm{min}$, and the detection wavelength was set at $278 \mathrm{~nm}$. The UV spectra were obtained by full wavelength scanning range from 190-400 $\mathrm{nm}$ using an Ultravioletvisible spectrophotometer (AOE-A360). The solution $\mathrm{pH}$ was determined by a $\mathrm{pH}$ meter (PHS-3E, Shanghai INESA Scientific Instrument Co., Ltd.). The concentration of DO was determined by a portable dissolved ozone analyzer (OXYTRANS TR).

\section{Results and discussion}

\subsection{Characterization}

The morphology of synthesized rGO@nZVI/Al can be observed in Fig. 1a, b. In the low magnified image (Fig.1a), it shows that abundant nano-sheets of rGO were assembled into the three-dimensional porous scaffold. With the image further magnifying, Fig. $1 \mathrm{~b}$ presented that numerous nano-particles with nearly spherical shapes were decorated on the multi-hierarchical porous structure of rGO matrix. The EDS spectrum (Fig. 1c) reveals that the atomic ratio of $\mathrm{Fe} / \mathrm{Al}$ is around 7.6, which is very close to the theoretical loading ratio of $\mathrm{Fe} / \mathrm{Al}$.

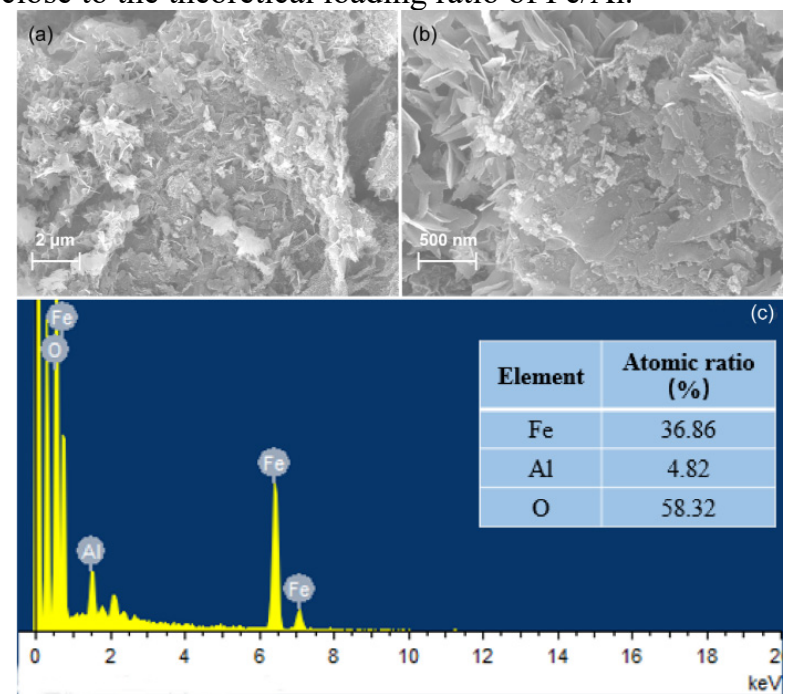

Fig. 1. (a) Low-magnification and (b) high-magnification SEM images of rGO@nZVI/Al; (c) EDS analysis for rGO@nZVI/Al

\subsection{The effective removal of CAP}

In Fig. 2a, on the one hand, CAP was completely degraded by $\mathrm{rGO} @ \mathrm{nZVI} / \mathrm{Al}$ in a rapid way under the Ar atmosphere, which suggested that rGO@nZVI/Al was featured with strong reducing property and capable of eliminating CAP directly. However, the mechanism of CAP reduction by nZVI-based composites was mainly related to de-chlorination and reduction of nitro group, which is not an efficient way for the mineralization of CAP[12]. Herein, on the other hand, a unique oxidation of CAP in the rGO@nZVI/Al-DO system was investigated. As is seen, over $80 \%$ of CAP was degraded in the rGO@nZVI/Al-DO system under neutral pH, which seemed that the presence of DO posed adverse effect on the CAP removal. However, the variation in UV spectra in different reaction systems (Fig. 2b) showed that CAP and its reductive intermediates were further degraded with less generation of by-products in the rGO@nZVI/Al-DO system. Considering the consumption of DO in the rGO@nZVI/Al-DO system, the promoted destroy of CAP and intermediates was contributed to the oxidation resulted from the DO activation by rGO@nZVI/Al. Many studies have 
confirmed that the presence of DO facilitated the oxidation of organic contaminants in some Fenton-like systems[7,13]. However, few of these investigations can achieve such effective degradation without adding extra oxidants or the limitation of acidic conditions. As seen in Fig. 3a, compared with rGO@nZVI and rGO@Al, rGO@nZVI/Al performed the highest removal efficiency of CAP at neutral $\mathrm{pH}$ under the $\mathrm{DO}$ condition. In addition, the presence of $3 \mathrm{mM} \mathrm{H}_{2} \mathrm{O}_{2}$ had no obvious enhancement of CAP degradation for the rGO@nZVI/Al-DO system, implying the highly efficient DO activation by $\mathrm{rGO} @ \mathrm{nZVI} / \mathrm{Al}$. The magnetic behaviour of the $\mathrm{rGO} @ \mathrm{nZVI} / \mathrm{Al}$ composite was investigated before and after the degradation reaction with the corresponding hysteresis loops shown in Fig. 3b. The magnetization of the fresh and used samples were 62.8 and $63.7 \mathrm{emu} / \mathrm{g}$, respectively. It confirms that the synthesized sample is magnetic, which ensures that the catalyst can be easily separated from the solution for reutilization due to the negligible change in magnetization after the reaction.
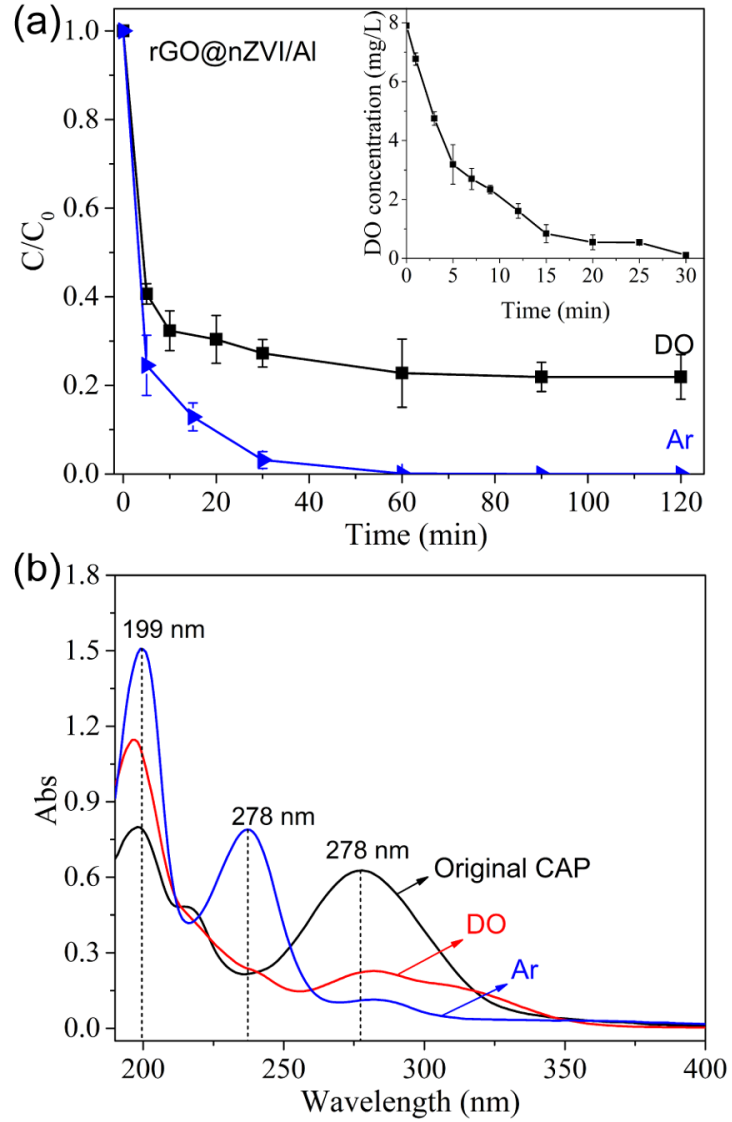

Fig. 2. (a) CAP removal under $\mathrm{DO} / \mathrm{Ar}$ condition and (insert Figure) the variation of DO concentration in the rGO@nZVI/Al-DO system; (b) UV spectra of CAP in the different systems
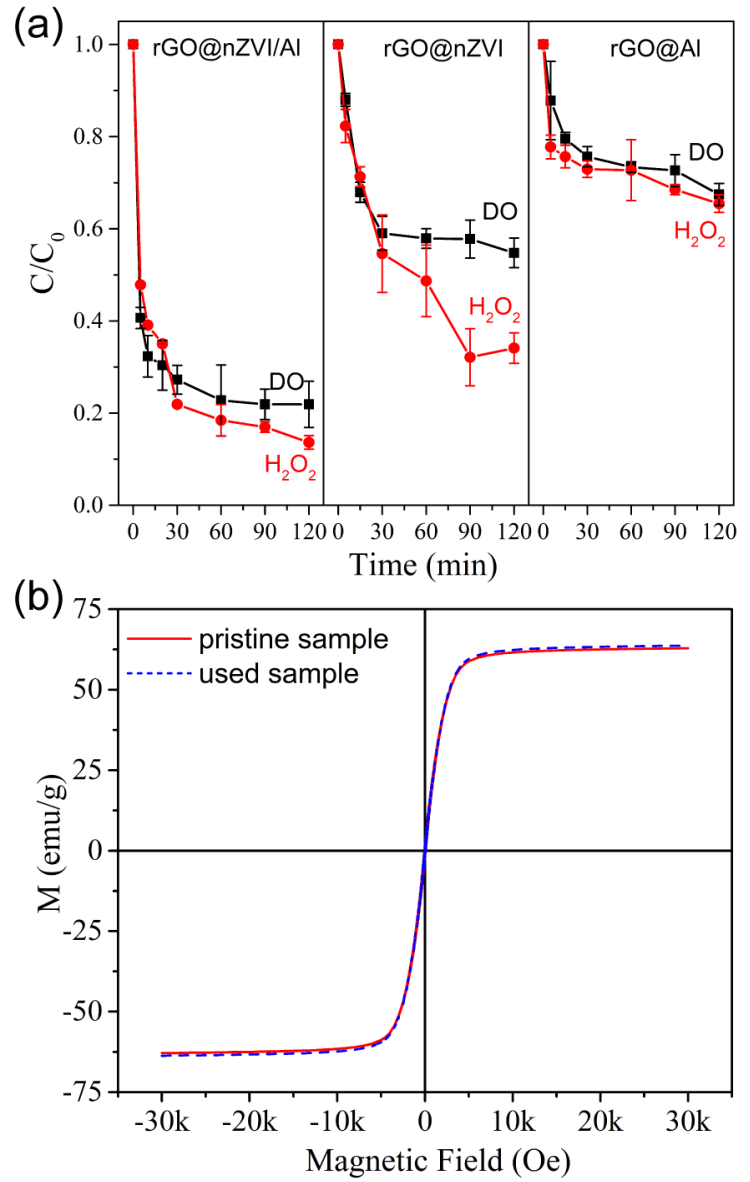

Fig. 3. (a) The degradation of CAP by rGO@nZVI/Al, $\mathrm{rGO} @ \mathrm{nZVI}$ and $\mathrm{rGO} @ \mathrm{Al}$ in the presence of $\mathrm{DO} / \mathrm{H}_{2} \mathrm{O}_{2}(3 \mathrm{mM})$;

(b) Magnetization curves for the pristine and used rGO@nZVI/Al

\subsection{Recycle of rGO@nZVI/AI}

After reaction, the catalyst was separated by magnet, washed, dried and used for the subsequent cycle. In the recycling tests, the removal experiments went through three cycles with the results shown in Fig. 5a. The removal efficiencies of CAP in the three cycles were $81 \%, 65 \%$ and $19 \%$, respectively. The continuous decrease of degradation efficiency was ascribed to the irreversible corrosion and passivation of rGO@nZVI/Al. As is well known, most of nZVI composites are generally short-lived due to their extremely high reactivity, which is failed to be reused in applications. However, in this work, it was noticed that rGO@nZVI/Al was still able to eliminate 65\% of CAP from water in the second cycle. According to the variation of UV spectra of CAP in the three cycles (Fig. 4b), the CAP removal in the first cycle might be mainly contributed to the catalytic degradation by the fresh rGO@nZVI/Al. Then the removal of CAP in the second cycle mainly depended on the adsorption bythe reused $\mathrm{rGO} @ \mathrm{nZVI} / \mathrm{Al}$. As a result, in the third cycle, rGO@nZVI/Al was completely deactivated due to the surface passivation caused by the adsorbed contaminants on the sample. In addition, the release of Fe ions was undetected during the recycling tests, indicating the negligible loss of Fe in $\mathrm{rGO} @ \mathrm{nZVI} / \mathrm{Al}$ in the application. 
(a)

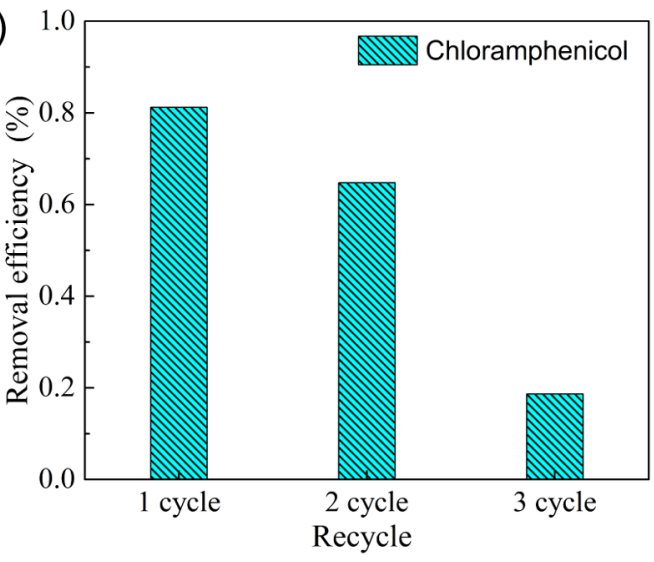

(b)

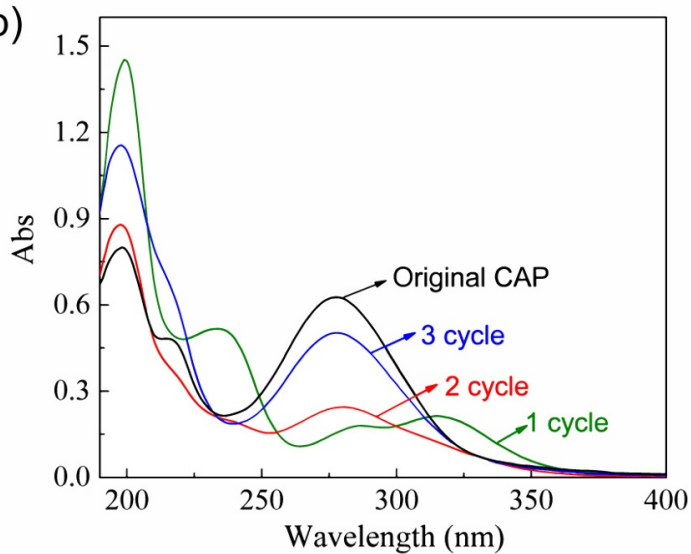

Fig. 4. (a) Reutilization property of $\mathrm{rGO} @ n Z V I / A 1$ for CAP removal; (b) UV spectra of CAP in the different systems

\section{Conclusions}

In this study, a ternary catalyst rGO@nZVI/Al was synthesized for effective degradation of CAP through $\mathrm{DO}$ activation. The morphology and chemical features of rGO@nZVI/Al were characterized by SEM-EDS, BET analysis and XRD pattern, showing its well-designed physicochemical structures. The CAP removal experiments revealed an excellent performance of DO activation and a promising catalytic degradation of CAP. Based on the cycling tests and the evolution of UV spectra, the reutilization of $\mathrm{rGO} @ \mathrm{nZVI} / \mathrm{Al}$ was investigated, which showed that rGO@nZVI/Al had potential application.

\section{Acknowledgment}

This work was supported by the National Natural Science Foundation of China (Grant No. 51708238).

\section{References}

1. Y. Gao, Y. Li, L. Zhang, H. Huang, J. Hu, S.M. Shah, X. Su, J. Colloid Interface Sci. 368 (2012) 540-546.

2. B. Czech, K. Rubinowska, Adsorption. 19 (2013) 619-630.
3. M. Rabiet, A. Togola, F. Brissaud, J.L. Seidel, H. Budzinski, F. Elbaz-Poulichet, Environ. Sci. Technol. 40 (2006) 5282-5288.

4. K.M. Onesios, J.T. Yu, E.J. Bouwer, Biodegradation. 20 (2009) 441-466.

5. Y. Sun, B. Zhang, T. Zheng, P. Wang, Chem. Eng. J. 320 (2017) 264-270.

6. B. Liang, H.Y. Cheng, D.Y. Kong, S.H. Gao, F. Sun, D. Cui, F.Y. Kong, A.J. Zhou, W.Z. Liu, N.Q. Ren, W.M. Wu, A.J. Wang, D.J. Lee, Environ. Sci. Technol. 47 (2013)

7. Y.J. Yang, L.J. Xu, W.Y. Li, W.J. Fan, S. Song, J. Yang, Appl. Catal. B Environ. 259 (2019) 118057.

8. P. Tabrizian, W. Ma, A. Bakr, M.S. Rahaman, J. Colloid Interface Sci. 534 (2019) 549-562.

9. V.K. Sharma, K.M. Siskova, R. Zboril, ACS Symp. Ser. 1150 (2013) 193-209.

10. K.V.G. Ravikumar, A. Sekhar Singh, D. Sikarwar, G. Gopal, B. Das, M. Pulimi, N. Chandrasekaran, A. Mukherjee, J. Environ. Manage. 236 (2019) 93-99.

11. H. Liu, W. Ding, S. Lei, X. Tian, F. Zhou, Nanomaterials. 9 (2019) 1-14.

12. M.B. Ahmed, J.L. Zhou, H.H. Ngo, W. Guo, A.H. Johir, K. Sornalingam, D. Belhaj, M. Kallel, Chem. Eng. J. 322 (2017) 571-581.

13. A. Shimizu, M. Tokumura, K. Nakajima, Y. Kawase, J. Hazard. Mater. 201 (2012) 60-67. 